\title{
The Effectiveness of Social Media and Multimedia-Based Pedagogy in Enhancing Creativity among Art, Design, and Digital Media Students
}

\author{
https://doi.org/10.3991/ijet.v14i21.10596 \\ Sama’a Al Hashimi ${ }^{(凶)}$, Ameena Al Muwali, Yasmina Zaki, and Nasser Mahdi \\ University of Bahrain, Sakheer, Kingdom of Bahrain \\ samaa.alhashimi@gmail.com
}

\begin{abstract}
Rapidly growing technological advances in big data, cloud computing, social media, artificial intelligence, virtual reality and digital media have led many educators to embark upon the pursuit and deployment of various digital tools in the classroom. They started implementing a technology-centered educational system in order to expand their pedagogical approaches and increase the possibilities of creatively putting ideas together and innovatively conveying their knowledge to their students. In this paper, we explore the convergence of creativity, technology, with art and design education, and we advocate the use of digital tools and repurposing of social media applications to support creative thinking. We discuss existing multimedia-based classroom practices that might encourage student creativity and suggest new forms and applications of technology aimed at providing the reflective teacher with more effective and efficient strategies to cultivate creativity while teaching art, design, and digital media courses.
\end{abstract}

Keywords - Creativity, multimedia, pedagogy, innovation, digital creativity, artistic creativity

\section{$1 \quad$ Introduction}

Creativity in the classroom is now a subject of intense interest to educators in many universities around the world. These educators seek to form a creative learning environment where students are more likely to express their ideas, think creatively, and effectively challenge problems with innovative solutions. This interest, which has been increasing in synchrony with the tremendous burst in technology, has made it necessary to re-conceptualize the role multimedia plays in infusing creativity into classrooms.

Despite this increased attention to creativity, there is still little understanding of how to use technology, and particularly social media platforms such as YouTube, Tumblr, Instagram, Pinterest, etc., in order to infuse creativity in current classroom contexts.

Emerging digital and multimedia technologies have played a significant role in redefining creativity in the classroom and in allowing for new and creative pedagogical 
practices. It has become necessary to encourage educators to develop a creative mindset for innovative pedagogical practices that exploit the potential of new technologies through repurposing existing digital tools and platforms for educational purposes.

This paper illustrates the potential of multimedia and social media tools and applications to be an engine that drives creativity and innovation in university settings. It particularly seeks to embed multimedia-based creative pedagogical approaches within art, design, and digital media learning contexts. We argue that multimedia-based learning has the potential to change key creative thinking processes and activities associated with art, design and digital media disciplines. This may broaden and expand how educators think about creativity in the classroom, and may lead to new definitions of creativity, especially when it becomes technologically-assisted, which is what we refer to as digital creativity.

This research is intended to contribute to the identification of good creative teaching practice in order to keep art, design, and digital media educators abreast of significant leaps in technology-assisted pedagogical approaches that nurture creativity. It aims to guide educators of how to effectively integrate digital creativity into teaching practice and how to make professional decisions related to their technology-driven activities and assignments.

The research starts by providing a redefinition of creativity and explores its role and relationship with technology-centred education. It studies how technology, creativity, and education interact, and establishes the theoretical framework for the research through providing an account of the diverse and innovative uses currently being made of multimedia across art, design and media disciplines. It offers a review of literature pertinent to multimedia-based approaches to teaching that support and encourage creativity, and examines models of the creative process in the digital classroom.

The research then involves an empirical investigation of the potential offered by digital media applications and social media platforms to enhance the creative learning experience in art, design and media. The investigation is undertaken in an experimental educational setting in an attempt to determine how technology can be utilized by educators in order to optimize the creative performance of art, design, and media students. The research also reports data from a qualitative case study which provides an in-depth account of practical and pedagogical issues involved in introducing multimedia-based learning into a fine arts painting course. The research findings give a great insight into effective strategies to inform and support educators' decisions about using technology to stimulate creativity in various phases of learning - whether it is conceptualizing, sketching, drawing, painting, designing, executing or assessing. These findings also enable educators to reconsider the prevailing uses of digital and social media tools and give them ideas to integrate technology effectively and creatively in the classroom in order to elevate the quality of teaching with appropriate digital tools and applications.

Based on the research findings, the paper is concluded by providing multimediaoriented recommendations that can benefit all academics in the subject areas of art, design, and digital media in higher education. Future directions and considerations are also proposed in an attempt to make a case for using multimedia technologies in art, 
design, and media courses to motivate higher levels of creative engagement amongst university students.

\section{Defining the Research Problem \& Significance}

As a result of the rapid technological advances, it has become necessary to employ new technologies in the educational process through implementing multimediaoriented teaching approaches in order to promote a creative thinking mind-set in students. Multimedia-supported teaching methods have proven to be among the most effective educational tools that can be utilized to form a stimulating learning environment for students and provide context and opportunities for greater creativity in the classroom as well as in all areas of life [20].

Unfortunately, few studies scientifically examine the effectiveness of setting up a multimedia-based educational environment that is conducive to fostering creativity in Art, Design and Media higher education. These studies lack a systematic scholarly investigation into the following questions, which we aim to raise in this research in order to gain further understanding of the role multimedia plays in promoting creative classroom practices:

- What technologies, multimedia applications, digital tools, and social media platforms can be harnessed to promote a creative mind-set in art, design, and media students?

- To what extent do these applications foster innovation and creativity?

- Which particular digital platforms are most effective in generating creative ideas for each of the various graphic design fields?

This research attempts to find answers to the above questions through investigating the practices of teachers at the University of Bahrain, surveying students, and conducting empirical research in the classroom.

\section{Examining Multimedia-Centered Pedagogical Directions in Creativity Research}

New technologies have influenced education enormously, especially with recent innovations and progress in social media affordances for content creation [11] and idea generation. Institutions are now changing and adjusting to new and creative learning approaches supported by technology tools. Livingstone [19] suggests that by involving the new technologies and merging the internet with the curriculum, we can build room for creativity in education.

According to Morris [22, p.4] creative teaching can be defined in two ways: firstly, teaching creatively and secondly, teaching for creativity;

"Teaching creatively might be described as teachers using imaginative approaches to make learning more interesting, engaging, exciting and effective. Teaching for 
creativity might best be described as using forms of teaching that are intended to develop students own creative thinking and behavior".

The educational context should stimulate and guide students and teachers to position themselves as creative interpreters and problem solvers. It should provide conditions and resources in which creative teaching and learning is promoted, fostered, guided and rewarded. According to Robson \& Jaaniste [23, p.5] "providing a wide range of appropriate materials, tools and other resources can stimulate creativity in learning activities (for example during art and design or design and technology)". Hennessy and Amabile [14] believe that social and environmental factors play a more significant role in creative performance than inherent personality traits, and they suggest that under the suitable circumstances, an individual's creativity can be improved. Henriksen et al. [15, p.9] argue that the first step towards locating creativity within educational systems is "to focus on the broader policy goals of integrating technology and creativity across the policy framework of education", and they emphasized the importance of the assessment of creative student works. Daviesa, et al.[8] highlighted several key characteristics of the environments and conditions that are most effective in promoting creative skills in children and young people. These include the physical environment, availability of resources/materials, use of the outdoor environment, flexibility in the physical and pedagogical environment, use of other environments beyond the school, play-based learning, effective and flexible use of time by allowing students to work at their own pace without pressure, relationships between teachers and learners, and working collaboratively with their peers.

In order to implement these characteristics in the learning process, teachers must repurpose technologies and employ teaching approaches that creatively engage students with content, and contribute to designing a transformative learning environment. Danvers [7] argues that the learning environment needs to support and encourage students' creativity, and involve interaction between learners. He noted:

"Creativity thrives in an atmosphere that is supportive, dynamic, and receptive to new ideas and activities. The learning environment has to encourage interactions between learners in which: action and reflection are carefully counter-balanced; openended periods of play and 'blue-sky' thinking alternate with goal-oriented problemsolving; stimulating inputs and staff interventions are interwoven with periods in which learners develop ideas and constructs at their own pace; critical thinking and robust debate co-exist with a supportive 'space' in which risk-taking, imaginative exploration and productive failure are accepted as positive processes of learning and, the development of meanings and interpretations is inseparable from material processes and production." [7, p.52].

Limited research exists on the use of social media platforms as learning or creativity enhancing tools. By using empirical analysis and observation to obtain student perceptions of the effectiveness of repurposing social media platforms and digital media apps as learning tools, this research adds to the knowledge base of existing literature. According to Abel [17];

"Widely adopted digital media formats, as well as the ability to share, publish, and co-create with a variety of proprietary and open-source web tools and services, are widely available, and with fewer technical barriers. Opportunities for educators are 
plentiful in leveraging social media technologies to expand spaces for learning (Abel, 2015 as cited in [17, P.35]."

Cochrane and Antonczak [5] consider the use of mobile social media to be both a creative pedagogical design experience for the instructors, and a creative learning experience for the students, as they believe that there is a limited use of it within educational contexts. They believe that the sharing, publishing, and co-creating features of digital tools increase educators' opportunities for leveraging social media technologies to expand learning environments and spaces. They advocate "the use of mobile social media for interaction and collaboration, and redesigning the curriculum around active student participation within authentic online global learning communities." [5, p.1]. As part of their study, they explored the use of Behance (an ePortfolio online community) for students to highlight their unique graphic design skills and showcase their creativity. They inferred that utilizing Behance profile effectively results in improving the quality and creativity of students' social media posts, as students were encouraged to link their Behance portfolios to Twitter, YouTube, Instagram, and Google Plus. They indicated that students were motivated by interacting with other Behance users who provided feedback on their portfolios.

As creativity in the classroom possibly originates from the teachers, enhancing the creative abilities of the students may be a challenging task for the teachers if their own creative abilities are undiscovered or restrained. The same idea has been suggested by Mishra et al. [21] who believe that there are two key aspects to the role of technology and creativity in the classroom. The first is the educator's creativity in producing new and creative pedagogical practices, while the second is the potential of technologies in providing new opportunities for enhancing students' creativity through affording contemporary ways to build, communicate, and share knowledge. Accordingly, there is strong evidence that modern technologies often bring new possibilities for people to be creative. In classroom terms, teachers must understand the range of ways in which technology can present content creatively and see how this intersects with different pedagogies.

Using the suitable teaching framework in the classroom usually constitutes a challenging decision to educators. Mishra \& Koehler [20] proposed the TPACK framework, which constitutes four components: Technology, Pedagogy, Content, and Knowledge. This framework has become a central framework for using technology effectively in the classroom. It focuses on knowledge types for effective teaching with technologies (from chalkboards to smart boards, pencils to Pixlr). The TPACK framework has received a significant level of scholarly and theoretical attention. Mishra et al. [21, p.24] suggest that TPACK "offers no specific directives about what content to teach (science or music), pedagogical approaches are useful (didactic or constructivist), and what kinds of technologies to use in teaching (digital or analog)."

In addition to the TPACK framework, Epstein [9] proposed the generativity theory, which is a predictive theory of creative behavior in individuals. It suggests that creativity is a skill that can be learned and measured. Epstein developed tests that "measure four essential competencies, capturing, challenging, broadening, and surrounding, which individuals require to be able to express their creativity". [17, P.35] 
Another model, the technology acceptance model (TAM) [18], was proposed by Davis [17];

"with the behavior intention model as the theoretical basis, this model explains the behavior of users when using technological products, and introduces three concepts adoption intention (AI), perceived ease of use (PEU), and perceived usefulness (PU), which all affect the attitude and acceptance of users when using technology" [17, P.34].

On the other hand, Cochrane and Antonczak [5] suggested the SAMR framework of educational technology adoption. It involves replication (Substitution), incrementation (Augmentation), and reinitiation (Modification and Redefinition). They noted that "the framework links a conceptual continuum of three levels of creativity, educational technology adoption (SAMR), and three phases of mobile learning with the pedagogy-andragogy-heutagogy (PAH) continuum" [5, p.21].

Cochrane and Antonczak [5] developed an ecology of resources (EOR) to assist students in establishing a professional digital profile. EOR categorises a range of platforms and apps according to their suitability in the creation and sharing of text (Twitter and Storify), image (Behance and Instagram), or video (Vine, YouTube, Vimeo, and Vyclone).

The above-mentioned frameworks provide a theoretically-informed guide for designing creative learning environments using mobile social media. However, In order to take the advantage of these new technologies, educators must develop a creative mind-set to teaching and learning [5].

Graphic design and fine arts are profoundly linked to creativity. Williams and Askland $[28$, p.4] argue that "Creativity forms part of design, design processes, and design education", while Hickman [16, p.71] emphasizes that "Creativity can exist in all forms of learning but is particularly developed within and through the arts". Graphic design is one of the most important disciplines that can develop the creative potential of students. Some studies (e.g [4]) considered graphic design as an effective discipline for improving creative design problem solving. One application of graphic design is web design, which is "viewed as an important method that teachers can use to link content knowledge with the construction of a tangible product and allow students to contextualize and amplify their creativity" [3, p.21].

Art and Design students need a wide range of knowledge, good creativity, and an enabling environment for communication and exchange of ideas. Social media provide us with the functions of recording, storage, instant sharing, and exchange, which facilitate the possibility of inspiration [26]. Students majoring in design and art can use social media to promote their creativity as some studies indicated that social media is correlated with creative expression [17].

Finally, there is a clear need for further research connected to these different learning contexts where creativity and technology co-exist in art and design disciplines. Throughout the rest of this paper, a re-orientation of art, design, and media design learning and teaching is proposed around a multimedia-based pedagogy that places particular emphasis on the utilization of social media tools in educational contexts. 


\section{$4 \quad$ Exploring Creativity in the Digital Classroom}

This part of the study examines how students who are specialized in Art, Design, and Digital Media in a higher education program use digital and social media to creatively engage in learning activities, and also investigates educators' employment of these technologies to enhance creativity within their classrooms. It identifies students' preferences in using various digital platforms and applications as inspirational sources.

\subsection{Sample}

Data was collected from multiple sources, including questionnaires, interviews, and empirical observation and analysis. The empirical research engaged two samples in two alternative experimental settings. In Study 1, a group of 42 art and design students were asked to go through brainstorming and design stages that involved the use of various digital tools in order to create and design unique cartoon characters. In Study 2, the integration of technology with fine arts was explored in a field setting with students engaged in "Phone Art"; a technique that involves using various apps to digitally manipulate photos before painting them. The findings of these two studies were derived from questionnaires, interviews, and observation [1].

Additionally, in order to complement the empirical research with quantitative analysis, a semi-structured online questionnaire was distributed. It involved a purposeful sample of students who are specialised in Fine Arts, Graphic Design, and Digital Media. Fifty-seven participants, forty female and seventeen male, participated in the survey, which aimed to identify students' attitudes towards multimedia-based pedagogy and explore its effectiveness in fostering their innovation and creativity. Their ages ranged between 19 and 25 years.

\subsection{Data analysis}

All the participants indicated that they use social and digital media applications to generate ideas while brainstorming. This supports Hakkerainen et al [13] research findings, which emphasize students' positive attitudes towards using technology in art and design education, and confirm the role of technology in improving students' performance, self expression, and motivation. Correspondingly, most of the participants $(75 \%, n=30)$ indicated that multimedia-based teaching helped them in generating more creative ideas (Figure 1).

When asked to rank the digital platforms according to their effectiveness in generating creative ideas, most students considered Instagram to be the most effective, followed by Pinterest, YouTube, Google images, and Tumblr. They considered Behance, WhatsApp, Facebook, and Evernote to be significantly less effective in generating creative ideas (Figure 2). 


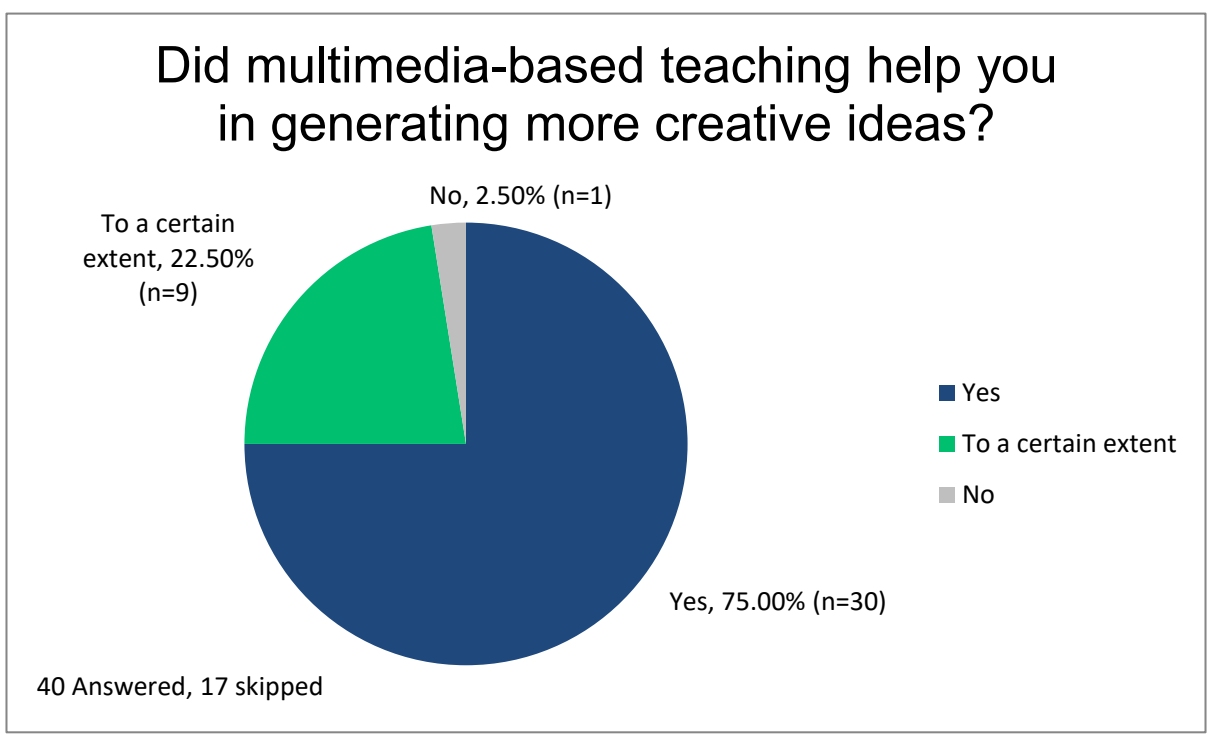

Fig. 1. Most of the participants indicated that multimedia-based teaching helped them in generating more creative ideas

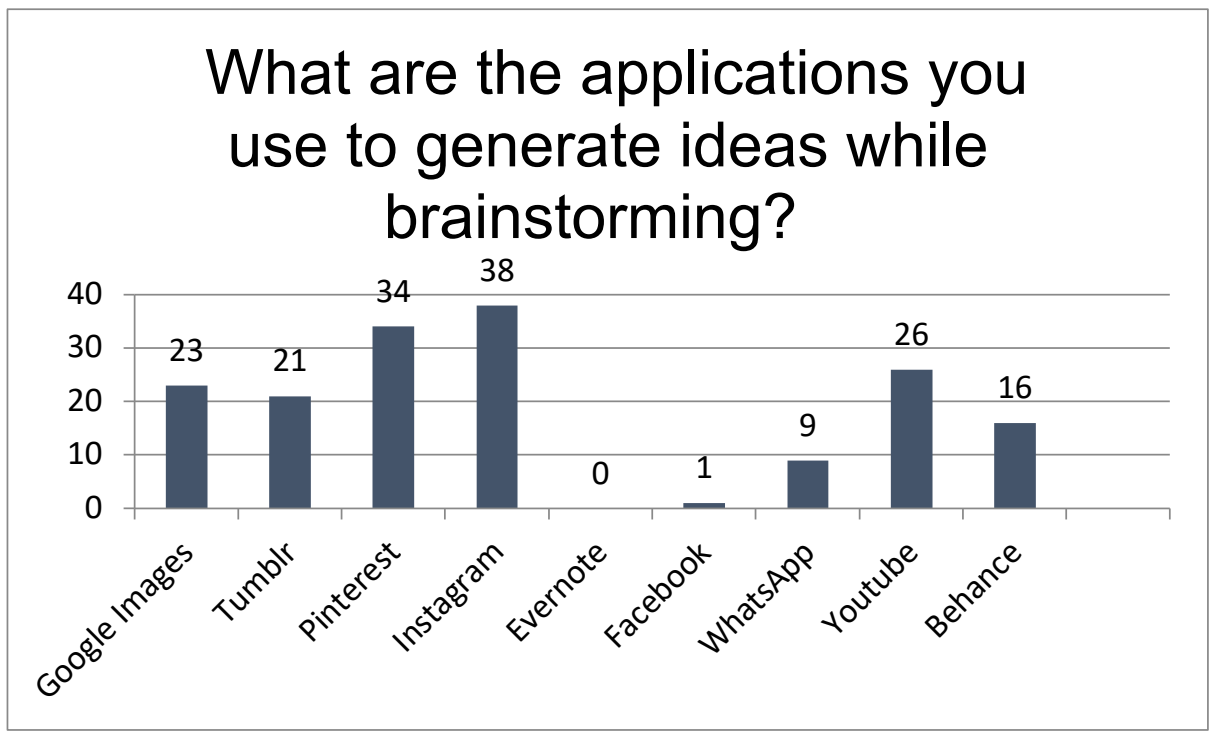

Fig. 2. The applications mostly used by the students to generate ideas while brainstorming

This result may be attributed to the general popularity of Instagram in Bahrain, which encourages students to use it during their learning process. The ease of using Instagram and its familiarity may also be a reason for students' preference to use Instagram. Jia-Xiang and Kuo-Kuang [17] discussed the correlation between the usability of social media and creative expression, and they suggested a positive connec- 
tion between perceived ease of use and perceived usefulness of the platform in design education. Another factor may be the graphical user interface of Instagram, which relies mainly on visuals with minimal distraction that is usually caused by menus and buttons. Such distractions in the interface may hinder exploration and fluidity of interaction, which are important factors especially during the exploratory stages of creativity. This is also emphasized by Igarashi [27] who explored supportive interfaces for creative visual thinking and indicated that "Nested menus, arrays of buttons, and dia$\log$ boxes interfere with the flexible exploration" [27, p.1]. The minimal use of menus and buttons and the predominance of an engaging visual appearance seems to be a common feature among Instagram, Pinterest, and YouTube, which the students considered most effective in generating creative ideas. Other common features include sharing, getting feedback, likes, and comments. These features are important factors in stimulating creativity and they relate to the four phases (collect, relate, create and donate) and the eight activities (search, consult, visualize, think, explore, compose, review, and disseminate), which Schneiderman [24] proposed as part of the genex framework that supports innovation.

Instagram, for instance, allows the user to "collect" inspirational images by saving them to collections. It also allows users to share and "disseminate" artworks at any stage and allows followers, peers, and even instructors to view and comment on posted images. Dissemination and sharing is considered an important stage in the creative process by some researchers who believe that "Creative work is not complete until it is disseminated" $[24, p .6]$. According to Schneiderman [24, p.3] the situationalists emphasizes the social context as a key part of the creative process suggesting that "vital user interfaces are those that support access to previous work in the domain, consultation with members of the field, and dissemination of results to interested members of the field".

When the surveyed students were asked if they published or shared any of their works in any multimedia application or social media, $68 \%(\mathrm{n}=25)$ of them answered "Yes", 27\%(n=10) answered "Sometimes", and only 5\% $(\mathrm{n}=2)$ answered "No". Most of them published their artworks on Instagram, Pinterest and Tumblr Respectively. Some of them noted that the objectives behind sharing their artworks include getting feedback that generates creative ideas, and to exchange artistic and creative ideas. Some participants also noted that they share their artworks in order to promote and market their creative ideas, while a few participants indicated that they share their works to achieve fame and gain a larger number of followers. One of the participants noted that he is using Instagram as an archive for his work.

Among the students who publish and share their artworks, 50\% $(\mathrm{n}=18)$ published their works in various stages, in order to reflect credibility and the progress of their work, $33 \%(\mathrm{n}=12)$ of them published after they finish the work, and only one participant shares artworks at their early stage. Most $(77 \%, \mathrm{n}=27)$ of the students believe that publishing and sharing their works in social media contribute to enhancing their creativity. Several papers [2] [25] [7] [10] have proven the effect of collaboration and cooperation through social media in promoting creative thinking. Some of these studies suggested that social processes and dissemination may help in the refinement 
stage, but Schneiderman [24, p.6] argued that they "can also be helpful at early, middle and late stages of the creative process."

In addition to dissemination, "the rapid exploration of alternatives", which Gross, M. and E. Do [12, p.1] mentioned in their research as an important feature in creative interfaces, is also embedded in the "explore" feature in Instagram. This draws attention to the user interface features and issues that may affect the effectiveness of a digital platform in enhancing creativity and necessitates further research into designing user interfaces to support creative processes.

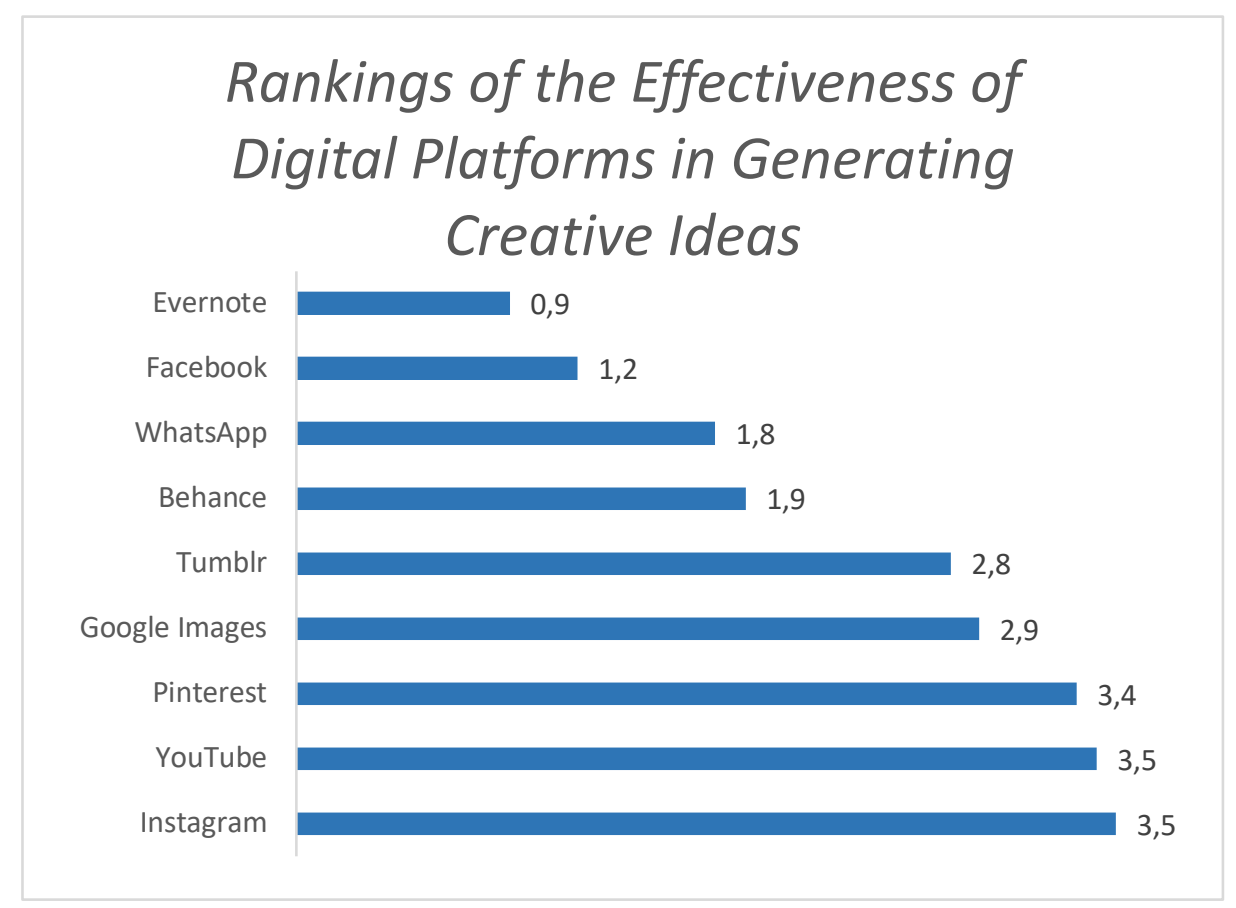

Fig. 3. Rankings of the digital platforms according to their effectiveness in generating creative ideas

The participants were also asked to rank their preferences for using social media apps within the different design categories (Figures $3 \& 4$ ). It is worthy to note that students considered Instagram to be the most effective in getting ideas for photography, awareness posters, cartoon characters, advertising, logo and brand design. YouTube was considered the most effective in getting inspiration for interactive projects, video production, infographics, animations, and web design. On the other hand, Pinterest is considered most effective in children book design, magazine design, typography, and equally effective with Instagram in awareness ad design. Facebook, WhatsApp and Evernote were generally considered less effective in stimulating creative ideas. 
This indicates that students' preferences for using digital or social media platforms to foster creativity may vary according to the particular design or art areas or fields. Therefore, educators are urged to find out and employ the most suitable multimediabased tools to enhance creativity in accordance with students' preferences and the specific course and assignment objectives.

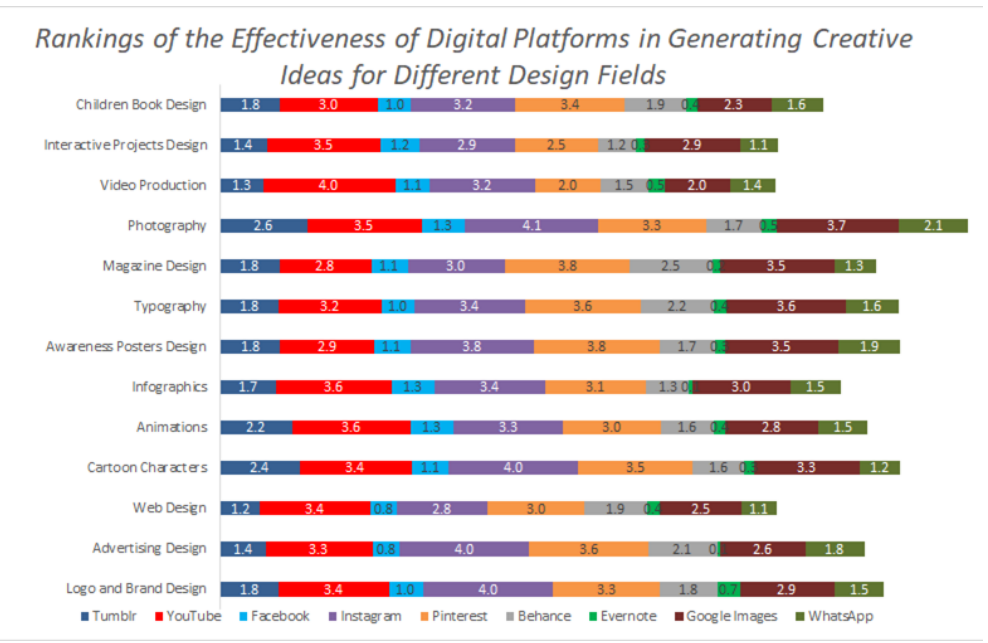

Fig. 4. Rankings of the digital platforms according to their effectiveness in generating creative ideas for various design fields

In addition, $50 \%(\mathrm{n}=20)$ of students indicated that their instructors always employ multimedia-based pedagogy to enhance their creativity, while $45 \%(n=18)$ indicated that their instructors employ it sometimes, and 5\% $(n=2)$ indicated minimal employment. This reflects the increasing awareness among instructors of the importance of technology in enhancing student creativity, and stresses the findings of prior studies, which have noted the importance of technology-centred education in enhancing creativity in design and art education [19] and [7].

When asked about the effectiveness of multimedia-based learning to stimulate their creativity, $65 \%(n=26)$ of the respondents considered it very effective, $30 \%(n=12)$ found it somewhat effective, $3 \%(\mathrm{n}=1)$ indicated that it was slightly effective, while $3 \%(n=1)$ thought that it is not effective. These results reflect the increasing awareness among students of the importance of the use of technology during the learning process in stimulating their creativity. Most of the students $(75 \%, n=30)$ agreed that multimedia-based pedagogy helps them to generate more creative ideas in faster pace. Moreover, $85 \%(n=34)$ of the students believe that multimedia tools increase their concentration. This result shows the students' positive attitudes towards using multimedia tools to stimulate their creativity. 


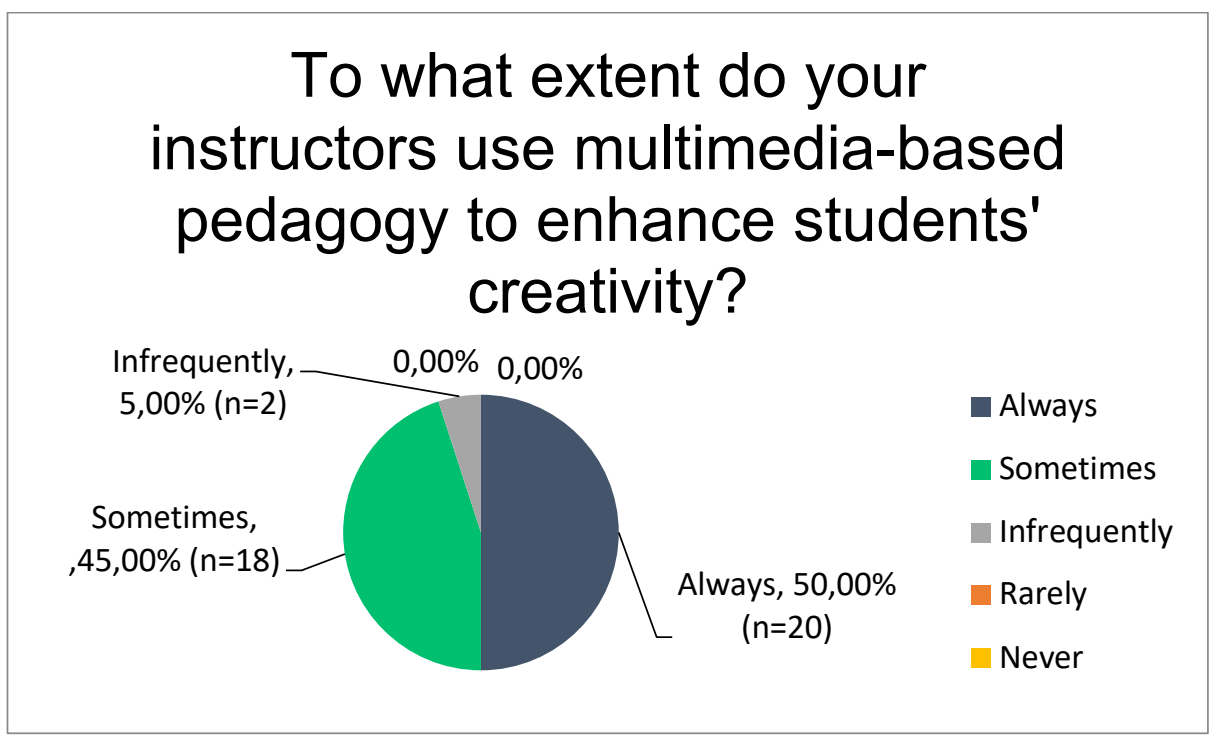

Fig. 5. The extent of use of multimedia-based pedagogy to enhance creativity by the instructors of the respondents

However, there were negative responses from students regarding the adequacy of the percentage of teachers who use multimedia-based pedagogy. The average of their estimated percentage of teachers who use multimedia tools to enhance creativity was $58 \%(n=38)$. Only 33\% $(n=13)$ of the students believe that enough teachers use these tools to enhance creativity (Figure 5). Most of the students think that the main obstacles that hinder the instructors from employing multimedia-based pedagogy to enhance creativity include the lack of teachers' interest to stimulate student's creativity (3.1), the lack of technological resources (3.1), followed by the weakness of teacher's knowledge of the digital applications that may enhance creativity (3), and the lack of proficiency in using multimedia technologies (3) respectively. The lack of educators' interest in simulating creativity may indicate a likely resistance to change which may exist in many cultures. Schneiderman [24, p.5] believes that "Many cultures encourage respect for the past and discourage disruptive innovations. Promoting widespread creativity raises expectations that may change employment patterns, educational systems, and community norms". Regardless of the possible obstacles that my hinder educators from employing digital media to stimulate creativity, $76 \%$ $(n=28)$ of the respondents expressed their desire for teachers to employ these techniques. One of the students said that "these methods help to develop the student's style and diversify teaching methods". Another student said, "These tools increase my interest and creativity".

These results indicate that digital applications can be effective in enhancing creativity in the classroom. Therefore, art, design, and digital media educators must be encouraged to repurpose these applications for educational purposes. 


\section{Conclusion}

The rapid evolution of the digital media technologies driven by today's proliferation of devices and applications has introduced a paradigm shift in art, graphic design, and digital media education from the use of the traditional teaching strategies to the gradual adoption of social media platforms and digital apps like Instagram, Tumblr, WhatsApp, Facebook, and Pinterest. The potential to use these tools and platforms to enhance creative learning is undeniable. Social networking, digital apps, and online environments hold promise for reaching beyond the walls of traditional classrooms, and for providing opportunities for educators to improve their pedagogical strategies by expanding the horizon of their approaches and switching to digital and social media platforms with all their creative and interactive potentials. However, the creativity-fostering capabilities of digital and social media have not been fully explored and exploited by art and design educators. The research therefore examined the effectiveness of repurposing digital tools and applications in order to foster creative teaching and teaching for creativity. It proposed, explored, and tested new teaching approaches, which aimed to give insights into how to capitalize on digital learning tools, applications, and experiences in crafting rigorous and creative classroom activities. It discussed the pedagogical implications that arise from the use of digital and social media and, in so doing, challenges traditional approaches of teaching and learning.

Although the results of this investigation are generally promising, it suffers from flaws that are relatively common in research in real classroom settings and educational environments. For instance, other digital tools and platforms may ultimately come to be seen as more significant than some of those proposed in this research.

To further validate these results, the methodology and findings are shared in this research in an attempt to encourage other educators to test similar methodological approaches and share their findings with the greater discipline. The findings in this research demonstrate that today's educators can repurpose digital tools and applications to design opportunities and cultivate educational cultures that foster collaboration and inspire creative outcomes in their own domains. In order to help educators achieve this, universities should implement a definite and extensive multimedia-based educational policy. Such an elaborate measure will ensure that universities explore fully the multimedia-based pedagogical prospects and opportunities in the areas of art, design, and digital media.

\section{References}

[1] Al Hashimi, S., Zaki, Y., Al Muwali, A., Mahdi, N. (2019) Infusing Creativity and Technology Through Repurposing Existing Digital Tools and Social Media Apps for Educational Purposes. In Brooks, A., Brooks, E., \& Sylla, C. (Eds) Interactivity, Game Creation, Design Learning, and Innovation, 7th EAI International Conference, DLI 2018, ICTCC 2018, Braga, Portugal, October 24-26, 2018, Proceedings. Lecture Notes of the Institute for Computer Sciences, Social Informatics and Telecommunications Engineering, London, Springer International Publishing. https://doi.org/10.1007/978-3-030-06134-0 36 
[2] Alamri, M. (2019). Undergraduate Students' Perceptions toward Social Media Usage and Academic performance: A study from Saudi Arabia. International Journal of Emerging Technologies in Learning (iJET) 14 (3), 61-79. https://doi.org/10.3991/ijet.v14i03. $\underline{9340}$

[3] Antonenko, P., \& Thompson, A. (2009). Preservice Teachers' Perspectives on the Definition and Assessment of Creativity and the Role of Web Design in Developing Creative Potential. Springer, 16(2), 203-224.

[4] Bandyopadhyay, B. (2008). Graphic Design: Practice and Methods. in NEW VIEWS 2 (Conversations And Dialogues in Graphic Design), An International Symposium Defining Graphic Design For The Future, London, University of the Arts London.

[5] Cochrane, T., \& Antonczak, L. (2015). Designing Creative Learning Environments. Interaction Design and Architecture(s) Journal- IxD\&A, 24, 125 - 144.

[6] Csikszentmihalyi, M. (1996). Creativity - Flow and the Psychology of Discovery and Invention. New York, NY, Harper Collins Publishers.

[7] Danvers, J. (2003). Towards a radical pedagogy: Provisional notes on learning and teaching in art \& design. International Journal of Art \& Design Education, 47-57. https://doi. org/10.1111/1468-5949.00338

[8] Daviesa, D., Jindal-Snapeb, D., Colliera,C., Digbya, R., Haya, Penny., \& Howea, A., (2013). Creative learning environments in education-A systematic literature review.

[9] Epstein, R. (1990) Generativity Theory and Creativity. In Runco, M.A. and Albert, R.S. (eds.), Theories of Creativity. Sage, Newbury Park, CA, 116-40.

[10] Fischer, G. (2005). Distances and Diversity: Sources for Social Creativity, Proceedings of Creativity \& Cognition, London, April, 128-136.

[11] Georgieva Aleksandrova, Y. \& Parusheva, S. (2019). Social Media Usage Patterns in Higher Education Institutions - An Empirical Study. International Journal of Emerging Technologies in Learning (iJET). 14. 108. https://doi.org/10.3991/ijet.v14i05.9720.

[12] Gross MD, Do EY-L (1996) Ambiguous intentions - a paper-like interface for creative design. Proceedings of ninth annual symposium for user interface software and technology (UIST 96), 22, 183-192. https://doi.org/10.1145/237091.237119

[13] Hakkarainen, P., Saarelainen T. with and Ruokamo H. (2007). Towards meaningful learning through digital video supported, case based teaching. Australasian Journal of Educational Technology, 23(1), 87-109. https://doi.org/10.14742/ajet.1275

[14] Hennessey, B. A., \& Amabile, T. M. (1988). The conditions of creativity. In R. J. Sternberg (Ed.), The nature of creativity. New York: Cambridge University Press.

[15] Henriksen, D., Mishra, P., with and Fisser, P. (2016). Infusing Creativity and Technology in 21st Century Education: A Systemic View for Change. Educational Technology \& Society, 19(3), 27-37.

[16] Hickman, R. (2008). Research in Art \& Design Education: Issues and Exemplars Readings in Art and Design Education Series, Bristol, UK: Intellect books.

[17] Jia-Xiang, C. and Kuo-Kuang, F. (2017). Constructing Creativity: Social Media and Creative Expression in Design Education.

[18] Liu, L., Zhang, L., Pinghao, Y. and Liu, Q. (2018). Influencing Factors of University Students' Use of Social Network Sites: An Empirical Analysis in China. International Journal of Emerging Technologies in Learning (iJET) 13 (3), 71-86. https://doi.org/10.3991/ijet. v13i03.8380

[19] Livingston, L. (2010). Teaching creativity in higher education. Arts Education Policy Review, 111(2), 59-62. https://doi.org/10.1080/10632910903455884 
[20] Mishra, P., and Koehler, M. J. (2006).Technological pedagogical content knowledge: A Framework for teacher knowledge. Teachers College Record, 108(6), 1017-1054. https:// doi.org/10.1111/j.1467-9620.2006.00684.x

[21] Mishra, P., Koehler, M. J., \& Henriksen, D. A. (2011). The Seven trans-disciplinary habits of mind: Extending the TPACK framework towards 21 st century learning. Educational Technology, 51(2), 22-28.

[22] Morris, W. (2006). Creativity - its place in education. New Plymouth. Retrieved from http ://www.creativejeffrey.com/creative/Creativity in Education.pdf

[23] Robson, J., and Jaaniste, L. (2010). Growing Future Innovators: A New Approach to Learning Programs for Young People. Edith Cowan University. Retrieved from http://www.pica.org.au/downloads/83/Growing_Future_Innovators_online_report_Aug_20 10.pdf

[24] Schneiderman, B. (2000). Creating Creativity: User Interfaces for Supporting Innovation. ACM Transactions on Computer-human Interaction - TOCHI, 7(1), 114-138. https://doi. org/10.1145/344949.345077

[25] Schön, D. A. (1983). The Reflective Practitioner: How Professionals Think in Action. New York, Basic Books.

[26] Stefania, M., and Maria, R. (2016). Facebook and the Others. Potentials and obstacles of Social Media for teaching in higher education. Computers \& Education, 95(Supplement C), 216-230. https://doi.org/10.1016/j.compedu.2016.01.012

[27] Igarashi, T. (2000). "Supportive Interfaces for Creative Visual Thinking" Collective Creativity Workshop, Nara (Japan), May 7-8, 2000

[28] Williams, A. and Askland, H. (2012). Assessing creativity: Strategies and tools to support teaching and learning in architecture and design, Final Report 2012, Newcastle: Australian Government Office for Learning and Teaching.

\section{$7 \quad$ Authors}

Sama'a Al Hashimi is an assistant professor in Digital Media and Graphic Design and the co-founder of the BA Art and Design Program at the Department of Communication, Tourism, and Arts at the University of Bahrain.

Ameena Al Muwali (ameena.almuwali@gmail.com), Yasmina Zaki (yasminazaki7@, gmail.com), and Nasser Mahdi (abuabdulla00@gmail) are Master students at the Department of Communication, Tourism, and Arts at the University of Bahrain.

Article submitted 2019-04-03. Resubmitted 2019-06-06. Final acceptance 2019-06-08. Final version published as submitted by the authors. 